\title{
Phosphorus fertilization and herbage production in Finland
}

\author{
Elena Valkama $^{1)}$, Perttu Virkajärvi ${ }^{2)}$, Risto Uusitalo ${ }^{1)}$, Kari Ylivainio ${ }^{1)}$, Eila Turtola ${ }^{1)}$ \\ ${ }^{1)}$ MTT Agrifood Research Finland, Plant Production/ Soil and Plant Nutrition, FI-31600, Jokioinen, \\ elena.valkama@mtt.fi; risto.uusitalo@mtt.fi; kari.ylivainio@mtt.fi; eila.turtola@mtt.fi \\ ${ }^{2)}$ MTT Agrifood Research Finland, North Savo Research Station, FI-71750, Maaninka, \\ perttu.virkajarvi@mtt.fi
}

\begin{abstract}
The herbage yield responses to phosphorus $(\mathrm{P})$ fertilization show large variation and, unlike to cereals, initial soil test P (STP) does not always predict such variation. By using meta-analysis, we reviewed quantitatively 38 Finnish field experiments related to the effects of $\mathrm{P}$ fertilization on herbage dry matter (DM) yields in the 1960s - 2000s. The current meta-analysis has several advantages over other type of research aiming to summarize the effect of $\mathrm{P}$ fertilization on herbage production. It involves large number of studies, diversity of soils and cultivation zones, and it enables to highlight the sources of variation in responses across the studies. Along with clay and coarse-textured mineral soils, we observed 20 studies on organic soils, whereas previous European and Canadian studies on the same topic involved mostly mineral soils. Moreover, we developed yield response models for different soil textures and initial STP levels.

The summarized effect of $\mathrm{P}$ fertilization (mean $50 \mathrm{~kg} \mathrm{P} \mathrm{ha}^{-1}$ ) on DM yields was $13 \%$ over the control ( $\mathrm{N}$ and $\mathrm{K}$ fertilization) with large variation across the studies from $-10 \%$ to $70 \%$. The major sources of variation were soil texture, soil acidity (for organic soils), initial STP and the yield level in control. For example, the yield response was three times larger on organic soils than on clay or coarsetextured mineral soils. Moreover, the yield response was double on slightly acidic organic soils $(29 \%, n=$ $8)$ compared to that on moderately acidic ones $(15 \%, n=11)$. Thus, for acidic organic soils, even with low STP, P fertilization may be practically useless until the soils are first limed.

Meta-regression proved that generally the responses reduced with increasing initial STP across the studies and reached zero at high STP $\left(\mathrm{P}_{\mathrm{Ac}}, 21 \mathrm{mg} \mathrm{l}^{-1}\right)$. However, in some studies with high control yields, no responses were observed even at low STP, since the responses decreased linearly with increasing control yields. Finally, the responses did not statistically differ between the cultivation zones, cut frequency, decades, or between the studies having different duration of experiments.

Variation in herbage yields that is often observed in $\mathrm{P}$ fertilizer experiments is only partly related to increasing $\mathrm{P}$ rates, but also other factors should be taken into account. Further studies should address to the role of, e.g., soil structure in yield development, as it is evident that additional relevant explanatory variables would be needed to adequately explain the variation in herbage yields.
\end{abstract}

Key words: meta-analysis; phosphorus fertilization; herbage yield; soil texture; soil test P; soil pH

\section{Introduction}

Phosphorus (P) is one of the essential nutrients that pants need for their growth. Many studies have demonstrated the variability of herbage yield responses to $\mathrm{P}$ fertilization, and initial STP has been previously considered to be a key factor determining such variability. In soils with low STP, the yield responses are generally pronounced, while in moderate and high STP soils, the responses are negligible (Hakkola, 1998; Power et al., 2005; Saarela, 2006). However, even on low STP soils, the responses are not always obvious (Hakkola, 1998; Malhi et al., 2009). Bolland et al. (1989) concluded that the yields of pastures are a consequence of complex interactions of various factors so that it is not surprising that soil STP may be a poor predictor of the yield. 
By using meta-analysis, we reviewed quantitatively 38 Finnish field experiments related to the effects of $\mathrm{P}$ fertilization on herbage yields. We examined the sources of variation in the responses (soil parameters, the decade when an experiment was conducted, climatic and other experimental conditions found in the reports), and developed the yield response models accordingly.

\section{Material and Methods}

The database consisted of published and unpublished reports of experiments conducted at MTT Agrifood Research Finland, at its Research Stations and on private farms in Finland. The reports were retrieved from the library of MTT, while the journal articles were searched in the reference lists of previously published articles in relevant Finnish journals.

The main herbage species were grasses, such as timothy (Phleum pratense L.), meadow fescue (Festuca pratensis L.), cocksfoot grasses (Dactylis glomerata), tufted hair grass (Deschampsia cespitosa), meadow-grass (Poa sp.), and legumes, such as white clover (Trifolium repens L.) and red clover (Trifolium pratense L.). The final database consisted of 38 experiments conducted between 1959 and 2012 at 19 sites. The soils were classified as clay, coarse-textured mineral and organic soils with a pH range of $4.4-6.8$. The experiments were divided according to initial STP into three classes as in the previous study (Valkama et al., 2011), and also according to soil $\mathrm{pH}$ into two groups: moderately acidic, MA (5.0 - 5.7, clay and coarse-textured mineral; $4.4-5.2$, organic); slightly acidic, SA (5.8 - 6.8, clay and coarsetextured mineral; $5.3-6.1$, organic). Controls were fertilized with nitrogen from 45 to $300 \mathrm{~kg} \mathrm{ha}^{-1}$ (mean of $138 \mathrm{~kg} \mathrm{ha}^{-1}$ ) and potassium from 35 to $240 \mathrm{~kg} \mathrm{ha}^{-1}$, (mean $107 \mathrm{~kg} \mathrm{ha}^{-1}$ ). Treatments were fertilized with P from 6 to $75 \mathrm{~kg} \mathrm{ha}^{-1}$ (mean $50 \mathrm{~kg} \mathrm{ha}^{-1}$ ).

The effects of $\mathrm{P}$ fertilization on the herbage DM yields were analyzed using meta-analysis, which is the statistical analysis of a large collection of independent studies for the purpose of integrating their findings. The meta-analysis was carried out using the Meta Win 2.0 statistical program.

Mitscherlich yield response model was used to describe the relationship between fertilizer rates and DM yield responses:

$$
y=a\left(1-\mathrm{e}^{-b x}\right)
$$

where $y$ is the yield response, $a$ is the maximum yield, $b$ is the constant that governs the rate of yield response (steepness of the yield response curve), and $x$ is the $\mathrm{P}$ fertilizer rate.

\section{Results and Discussion}

The summarized effect of P fertilization (mean $50 \mathrm{~kg} \mathrm{P} \mathrm{ha}^{-1}$ ) on DM yield was $13 \%$ over the control with large variation across the studies from $-10 \%$ to $70 \%$. The variation among the soil texture groups was statistically significant $(p=0.005)$ and the response on organic soils was three-fold $(19 \%)$ compared to clay or coarse-textured mineral soils (6\%), but no difference within the two groups of mineral soils was found. The results were similar to the previous meta-analysis on the effect of $\mathrm{P}$ fertilization on cereal crops (Valkama et al., 2009). The variation in yield response among the soil types is most probably due to differences in the capacity of the soils to supply P.

The meta-analysis further confirms that soil acidity is an important factor for the herbage yield responses to $\mathrm{P}$ fertilization on organic soils, since the response was double on slightly acidic soils $(29 \%, n$ $=8$ ) compared to that on moderately acidic ones $(15 \%, n=11)$. As the $\mathrm{pH}$ falls to low levels, the solubility of aluminum (Al) and manganese (Mn) increases, and excess $\mathrm{Al}^{3+}$ and $\mathrm{Mn}^{2+}$ in the soil solution interferes with root and shoot growth and function, as well as restricts crop uptake of nutrients and water (e.g., Chesworth, 2008). Likewise, the response of white clover to $\mathrm{P}$ was greatest at the higher $\mathrm{pH}$ (Bailey and Laidlaw, 1999). Thus, liming should be a first investment before any P fertilizer applications, which may well turn out useless in soils with low $\mathrm{pH}$.

Initial STP was previously considered to be a key factor determining the yield response variability, although with some uncertainty regarding responses in case of low STP (Hakkola, 1998; Malhi et al., 
2009). Meta-regression proved that the responses to annual $\mathrm{P}$ applications generally decrease with increasing STP across the studies $(p=0.003)$, and cease at $21 \mathrm{mg} \mathrm{P}_{\mathrm{Ac}} \mathrm{l}^{-1}$ or at higher values. However, even at low STP, not all studies conducted on mineral soils or on moderately acidic organic soils showed herbage yield responses to applied P.

We found that the responses to $\mathrm{P}$ decreased with increasing control yields (NK) so that $\mathrm{P}$ addition becomes useless for the yield level of $12 \mathrm{t} \mathrm{ha}^{-1}$. In the same manner, our earlier work on cereals showed that there is a connection between the control yield levels and the magnitude of yield responses to $\mathrm{P}$ fertilization (Valkama et al., 2009). The same was also reported by Rubæk and Sibbesen (2000) for Danish long-term fertilization experiments. It can be speculated that the lack of response to $\mathrm{P}$ fertilization may be due to mineralization of organic $\mathrm{P}$ or a significant role of arbuscular mycorrhizal fungi in enhancing P turnover and availability, as discussed by, e.g., Lkhagvasuren et al. (2011).

The responses did not statistically vary between the studies with different cut frequency $(p=0.221)$ or conducted in different decades $(p=0.333)$. Finally, no statistically significant differences appeared between the cultivation zones $(p=0.07)$, nor between the studies having different duration of experiments $(p=0.15)$.

To provide advice for farmers, crop yield response model, i.e. the relationships between crop yield and the amount of P applied, must be defined. Phosphorus applications accounted for about $40 \%$ of the yield variation for the low STP soils. The maximum yield (a) was $18 \pm 7 \%$ over the control for mineral soils and $28 \pm 3 \%$ for organic soils. For soils with medium and high STP, the yield responses were scattered around zero, thus no relationship with $\mathrm{P}$ rates was found.

Only a small part of the variation in total annual herbage yield could be explained by fertilizer P. In Irish experiments, STP, fertilizer P and year-effects together explained on average $34 \%$ of the variation in herbage yields (Schulte and Herlihy, 2007). Moreover, the "year effect" often causes greater differences between average yields than the fertilizer application levels (Németh, 2006), and about 50\% of variation in grass yields may be related to availability of water (Sun et al., 2013). This suggests a profound effect on yield variation by other factors than $\mathrm{P}$ fertilization, such as interaction between precipitation and temperature, soil structure, or other site-specific factors that may differ considerably between the years and the experiments.

\section{Conclusions}

Variation in herbage DM yields that is often observed in P fertilizer experiments is only partly related to increasing P rates, but also other factors should be taken into account. Although initial STP was generally negatively correlated with the herbage responses, also low STP soils may show negligible yield responses if control yield is already high. We acknowledge the limitations of our models to explain yield variations that certainly have their root in many factors that were not recorded in the reviewed studies. Further studies should address to the role of, e.g., soil structure in yield development, as it is evident that additional relevant explanatory variables would be needed to adequately explain the variation in herbage yields.

\section{Reference}

Bailey, J.S. \& Laidlaw, A.S. 1999. The interactive effects of phosphorus, potassium, lime and molybdenum on the growth and morphology of white clover (Trifolium repens L.) at establishment. Grass and Forage Science 54: 69-76.

Bolland, M.D.A., Allen, D.G. \& Gilkes, R.J. 1989. The influence of seasonal conditions, plant species and fertilizer type on the prediction of plant yield using Colwell bicarbonate soil test for phosphate. Fertilizer Research 19: 143158 .

Chesworth, W. 2008. Encyclopedia of soil science. The Netherlands: Springer. 
Hakkola, H. 1998. Annual and storage application of phosphorus to ley. Kungliga Skogs- och Lantbruksakademiens Tidskrift 137: 99-104.

Lkhagvasuren, B., Schoenau, J. J., Anderson, D. W. \& Malhi, S. S. 2011. Plant and soil responses to nitrogen and phosphorus fertilization of bromegrass-dominated haylands in Saskatchewan, Canada. Grass and Forage Science 66: $351-360$.

Malhi, S.S., Coulman, B. \& Schoenau, J.J. 2009. Maximizing timothy forage yield and quality by balanced nitrogen, phosphorus, and sulfur fertilization. Agronomy Journal 101: 1182-1189.

Németh, T. 2006. Application of the Bray-Mitscherlich equation approach for economically and environmentally sound fertilization of field crops in Hungary. Communication in Soil Science and Plant Analysis, 37: 2227-2247.

Power, V., Tunney, H. \& Jeffrey, D.W. 2005. The phosphorus requirements for silage production on high fertility soils. Irish Journal of Agricultural and Food Research 44: 281-296.

Rubæk, G.H. \& Sibbesen, E. 2000. Long-term phosphorus fertilization - effects on crop yield and soil phosphorus status. DIAS report Plant Production, 31, Danish Institute of Agricultural Sciences, Foulum, 2000.

Saarela, I., Salo, Y. \& Vuorinen, M. 2006. Effects of repeated phosphorus fertilization on field crops in Finland. 1. Yield responses on clay and loam soils in relation to soil test P values. Agricultural and Food Science in Finland 15: 106-123.

Schulte, R.P.O. \& Herlihy, M. 2007. Quantifying responses to phosphorus in Irish grasslands: Interactions of soil and fertilizer with yield and P concentration. European Journal of Agronomy 26: 144-153.

Sun, Y., Cheng, Q., Lin, J., Schellberg, J. \& Lammers, P.S. 2013. Investigating soil physical properties and yield response in a grassland field using a dual-sensor penetrometer and EM38. Journal of Plant Nutrition and Soil Science 176: 209-216.

Valkama, E., Uusitalo, R. \& Turtola, E. 2011. Yield response models to phosphorus application: a research synthesis of Finnish field trials to optimize fertilizer P use of cereals. Nutrient Cycling in Agroecosystems 91: 1-15.

Valkama, E., Uusitalo, R., Ylivainio, K., Virkajärvi, P. \& Turtola, E. 2009. Phosphorus fertilization: A metaanalysis of 80 years of research in Finland. Agriculture, Ecosystems and Environment 130: 75-85. 